\title{
СВЯЗЬ ВИТАМИНА D И ОСТЕОПРОТЕГЕРИНА С МЕТАБОЛИЧЕСКИМИ ОСЛОЖНЕНИЯМИ У ДЕТЕЙ С ОЖИРЕНИЕМ
}

\author{
${ }^{1}$ Михно А.Г., ${ }^{2}$ Солнцева А.В. \\ ${ }^{1}$ У3 «2-я городская детская клиническая больница», Минск, Республика Беларусь \\ ${ }^{2}$ Белорусский государственный медицинский университет, Минск, Республика Беларусь
}

Цель: оценить связь витамина D и остеопротегерина с показателями метаболического статуса у детей с ожирением и нормальной массой тела.

Материалы и методы: В клинический этап изучения включена исследуемая группа 221

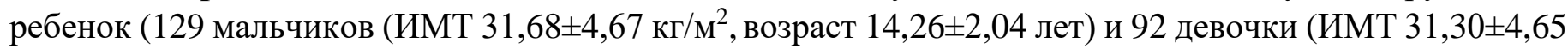

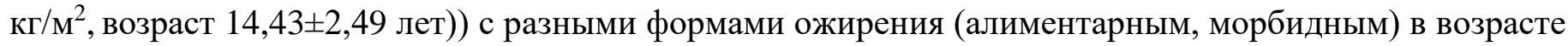

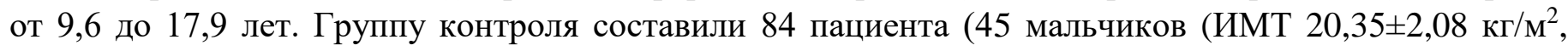

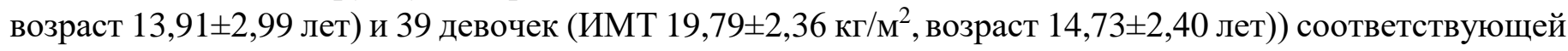

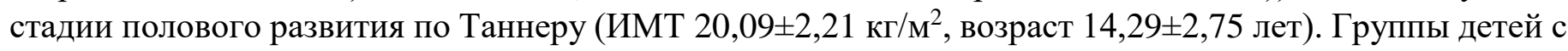
разными формами ожирения и нормальной массой тела были сопоставимы по полу $\left(\chi^{2}=0,572 ; p=0,45\right)$ и возрасту ( $\mathrm{U}=9088,50 ; \mathrm{p}=0,779)$.

Оценены лабораторные маркеры метаболического статуса: инсулин (ИРИ), гликированный гемоглобин $\left(\mathrm{HBA}_{1 \mathrm{C}}\right)$. Определены показатели витамина Д, остеопротегерина (ОПГ), лептина, адипонектина, паратгормона (ПТГ).

Статистическая обработка данных выполнена с помощью программы IBM SPSS Statistics 22.

Результаты: С помощью корреляционного анализа изучена связь между показателями витамина D и метаболического статуса у детей с разными формами ожирения. У пациентов с ожирением отмечена отрицательная связь концентраций витамина D и лептина $\left(\mathrm{r}_{\mathrm{s}}=-0,272, \mathrm{p}=0,027\right)$. Выявлена обратная корреляция между значениями витамина D и ПТГ у детей с алиментарным $\left(\mathrm{r}_{\mathrm{s}}=-\right.$ $0,289, \mathrm{p}=0,013)$ и морбидным ожирением $\left(\mathrm{r}_{\mathrm{s}}=-0,227, \mathrm{p}=0,024\right)$. У детей контрольной группы установлена статистически значимая прямая связь концентрации витамина D и ОПГ $\left(\mathrm{r}_{\mathrm{s}}=0,340\right.$; $\mathrm{p}=0,019)$.

Проведя анализ по уровню витамина D, мы выделили подгруппы пациентов с нормальным содержанием витамина D ( $\geq 30$ нг/мл) и недостатком ( $<30$ нг/мл). У детей с нормальным содержанием витамина D установлена отрицательная связь с лептином $\left(\mathrm{r}_{\mathrm{s}}=-0,317, \mathrm{p}=0,032\right)$, ПТГ $\left(\mathrm{r}_{\mathrm{s}}=-0,284, \mathrm{p}=0,048\right)$ и прямая с ОПГ ( $\left.\mathrm{r}_{\mathrm{s}}=0,406, \mathrm{p}=0,021\right)$; ОПГ и ПТГ $\left(\mathrm{r}_{\mathrm{s}}=-0,384, \mathrm{p}=0,025\right)$; прямая связь адипонектина и ОПГ $\left(\mathrm{r}_{\mathrm{s}}=0,506, \mathrm{p}=0,008\right) ;$ лептина и ПТГ $\left(\mathrm{r}_{\mathrm{s}}=0,282, \mathrm{p}=0,045\right)$.

B подгруппе детей с недостаточным содержанием витамина D установлена прямая связь лептина и ПТГ $\left(\mathrm{r}_{\mathrm{s}}=0,692, \mathrm{p}=0,009\right)$; обратная связь ОПГ и ПТГ $\left(\mathrm{r}_{\mathrm{s}}=-0,479, \mathrm{p}=0,038\right)$, лептином $\left(\mathrm{r}_{\mathrm{s}}=-\right.$ $0,574, \mathrm{p}=0,016)$; адипонектина и ПТГ $\left(\mathrm{r}_{\mathrm{s}}=-0,484, \mathrm{p}=0,042\right)$. При недостатке витамина D ( $<30$ нг/мл), у пациентов с алиментарным ожирением подтверждена статистически значимая прямая связь ОПГ с $\operatorname{HBA}_{1 \mathrm{C}}\left(\mathrm{r}_{\mathrm{s}}=0,39 ; \mathrm{p}=0,003\right)$, адипонектином $\left(\mathrm{r}_{\mathrm{s}}=0,603 ; \mathrm{p}=0,013\right)$ и отрицательная связь с концентрацией ПТГ $\left(\mathrm{r}_{\mathrm{s}}=-0,582, \mathrm{p}=0,023\right)$. Установлена обратная корреляция значений ОПГ с лептином $\left(\mathrm{r}_{\mathrm{s}}=-0,203\right.$, $\mathrm{p}=0,04)$, ПТГ $\left(\mathrm{r}_{\mathrm{s}}=-0,317, \mathrm{p}=0,001\right)$, прямая с инсулином $\left(\mathrm{r}_{\mathrm{s}}=0,47 ; \mathrm{p}=0,01\right)$, витамином $\mathrm{D}\left(\mathrm{r}_{\mathrm{s}}=0,821\right.$; $\mathrm{p}=0,023)$, адипонектином $\left(\mathrm{r}_{\mathrm{s}}=0,821 ; \mathrm{p}=0,023\right)$ у детей с морбидным ожирением. У детей контрольной группы статистически значимой связи ОПГ при уровне витамина D ниже нормы не выявлено.

Заключение: Данные нашего исследования показывают, что низкий уровень витамина Д связан с изменением в метаболическом статусе у детей с ожирением. Связь ОПГ с метаболическими изменениями зависит от концентрации витамина D. 